\title{
Lumen-apposing metal stents for gastrointestinal luminal strictures: current use and future directions
}

\author{
Brian Larson, Douglas G. Adler \\ University of Utah School of Medicine, Salt Lake City, Utah, USA
}

\begin{abstract}
The management of short-segment benign gastrointestinal (GI) strictures refractory to currently available endoscopic treatments (endoscopic balloon dilation, intralesional steroid injection, incisional therapy and fully covered self-expanding metal stents) proves to be challenging. Lumenapposing metal stents (LAMS), originally developed for access to and drainage of pancreatic fluid collections, are being used in an off-label manner for the treatment of short GI luminal strictures. The short length and wide flanges make LAMS potentially suitable for this indication and may reduce complications and improve patient tolerance. In this article we review the published literature, including 138 patients from 4 retrospective studies and 13 case reports who received a LAMS for the treatment of a short GI luminal stricture. In the reviewed literature only 2 of the 138 cases had immediate adverse events warranting hospitalization: perforation and postoperative GI bleed. A total adverse event rate of $32.5 \%$ (45 of 138 cases) was reported. Migration was the most common adverse event, accounting for $40 \%$ of the total. Nearly $58 \%$ of reported patients had symptom and stricture resolution after stent removal in the reviewed studies. Follow up varied from 28-352 days after stent removal. Although more data are needed to determine their long-term safety and efficacy, LAMS represent an important alternative to traditional endoscopic options when approaching patients with short GI luminal strictures.
\end{abstract}

Keywords Lumen-apposing metal stent, gastrointestinal strictures, benign strictures

Ann Gastroenterol 2019; 32 (2): 1-6

\section{Introduction}

Benign gastrointestinal (GI) strictures can arise anywhere in the lumen of GI tract as a result of various etiologies. Endoscopic management is the mainstay of therapy and management options currently include endoscopic balloon dilation (EBD), intralesional steroid injection, incisional therapy, and fully covered self-expandable metal stents (SEMS) [1-4]. Although these treatment modalities are effective, stricture recurrence is not uncommon. Stents have been increasingly used for refractory benign GI strictures, although long-term success is

Department of Gastroenterology and Hepatology, University of Utah School of Medicine, Salt Lake City, Utah, USA

\section{Conflict of Interest: None}

Correspondence to: Douglas G. Adler MD, FACG, AGAF, FASGE, Professor of Medicine, Director of Therapeutic Endoscopy, Director, GI Fellowship Program, Gastroenterology and Hepatology, University of Utah School of Medicine, Huntsman Cancer Center, 30N 1900E 4R118, Salt Lake City, Utah 84132 USA, e-mail: Douglas.adler@hsc.utah.edu

Received 28 July 2018; accepted 22 October 2018; published online 14 December 2018

DOI: https://doi.org/10.20524/aog.2018.0337 only achieved in $23-40 \%$ of cases [4,5]. Innovations such as the over-the-scope clip [6] and endoscopic suturing [7] minimize migration rates-which, however, still exceed 15\% [6,7].

Lumen-apposing metal stents (LAMS) are available in the US and were developed for access to and drainage of pancreatic fluid collections $[8,9]$. However, LAMS have been increasingly used for other conditions, such as gallbladder drainage [10], intestinal obstruction [11], abscess drainage [12], and benign refractory GI strictures [13]. LAMS are fully covered, short and have a wide flange at each end. The short length and wide flanges make LAMS potentially suitable for the treatment of short GI strictures and may reduce the risk of migration and improve patient tolerance. We herein review the available literature about the use of LAMS to treat strictures throughout the GI tract.

\section{Methodology}

An extensive search of the English language literature until 2018 was performed, using PubMed and Google Scholar to identify peer-reviewed original and review articles based on the key words "gastrointestinal stricture", "benign stricture", "lumen-apposing metal stent", "AXIOS", "NAGI" and "SPAXUS". Only articles that concerned human study subjects 
were selected. The reference lists of relevant studies were then searched manually to identify any additional appropriate publications. A total of 4 retrospective studies and 13 case reports were identified in the search and included in the review. The stricture etiology, location, success rate, complications, and limitations in each study were reviewed.

\section{Endoscopic technique}

LAMS are designed for deployment through a therapeutic forward-viewing endoscope or oblique-viewing linear echoendoscope. The technique of LAMS deployment has been reviewed elsewhere [8]. In most cases, the endoscopist advances the endoscope until the stricture is visualized directly. A guidewire is then introduced across the stricture under fluoroscopic guidance. If the endoscope can traverse the stricture, a guidewire may be obviated. The stent is then positioned and deployed across the stricture under endoscopic or fluoroscopic guidance. Endoscopists may alternatively dilate the stricture with a balloon to allow for LAMS placement.

\section{Esophageal strictures}

Refractory benign strictures and anastomotic strictures have been targets of LAMS placement (Fig. 1). To date, 22 patients in the reviewed literature had a LAMS placed for an esophageal stricture [13-16]. Anastomotic strictures were the most common indication, seen in 17 of the 22 patients. Other indications for placement of LAMS in the esophagus included refractory benign esophageal strictures, caustic injury and radiation-associated strictures. All but one of the patients had been previously treated with some form of endoscopic therapy, including EBD, intralesional steroid injection, or traditional SEMS placement and remained symptomatic. Adverse events occurred in 7 of the 22 patients, including stent migration, stent angulation and recurrent stricture. Fifteen patients reported improvement or resolution of symptoms after stent removal, with varying stent indwell time. No stricture recurrence was reported in these patients. Symptom improvement was not reported in 1 of the 22 patients.

Adler reported a series of 4 patients who had short esophageal strictures treated with a LAMS [13]. Clinical success was achieved in all patients. All 4 patients tolerated a soft mechanical diet with the stent in place and continued to have resolution of dysphagia at 4 weeks of follow up after stent removal. No adverse events were reported-chest pain, gastroesophageal reflux disease or other-and 3 patients reported not being able to perceive the presence of the stent. All stents were removed at 2 or 3 months and no recurrence was reported.

Santos-Fernandez et al reported 9 patients with esophageal strictures treated with a LAMS [14]. LAMS were left in place for 60 days or more and only 3 patients had symptom improvement or resolution after stent removal with the stent in place for longer than 60 days. Two patients experienced stent migration, 2 experienced stent angulation and 1 patient had recurrence of a stricture proximal to the stent. In 1 patient it was not reported if symptom resolution was achieved.

Irani et al reported 4 patients who underwent LAMS placement for esophageal anastomotic strictures with median indwell time of 90 days [15]. Three of the 4 patients had resolution of symptoms without adverse events. 1 patient died from metastatic esophageal cancer with the stent in place, but was symptom free until then. Two patients had complete resolution of symptoms at a median of 290 days of follow up and 1 patient developed a stricture proximal to the LAMS necessitating removal.

Yang et al reported 5 patients who underwent LAMS for esophageal anastomotic or esophageal gastric junction strictures [16]. Only 1 patient had an associated adverse event: stent migration. All other patients, at a median of 100 days of follow up after stent removal, had symptom and stricture improvement or resolution and did not require any additional intervention (Table 1).

\section{Gastric strictures}

To date, 20 patients in the reviewed literature had a LAMS placed to treat a gastric stricture [14-20]. The etiology of the strictures included anastomotic strictures, caustic injury, peptic ulcer disease with resultant peptic stricture formation, pyloric stenosis and 1 case of malignant pyloric stenosis (Fig. 2). Thirteen patients had been previously treated with endoscopic therapy: 8 patients with EBD, 4 patients with EBD and intralesional steroid injections, and 1 patient with a SEMS.

Of the 20 patients who had a LAMS placed for a gastric stricture, only 2 had an adverse event. One patient developed an ulcer without an overt bleed at the site of the stent, warranting stent removal. One patient developed bleeding in the postoperative recovery room. This patient was hospitalized,

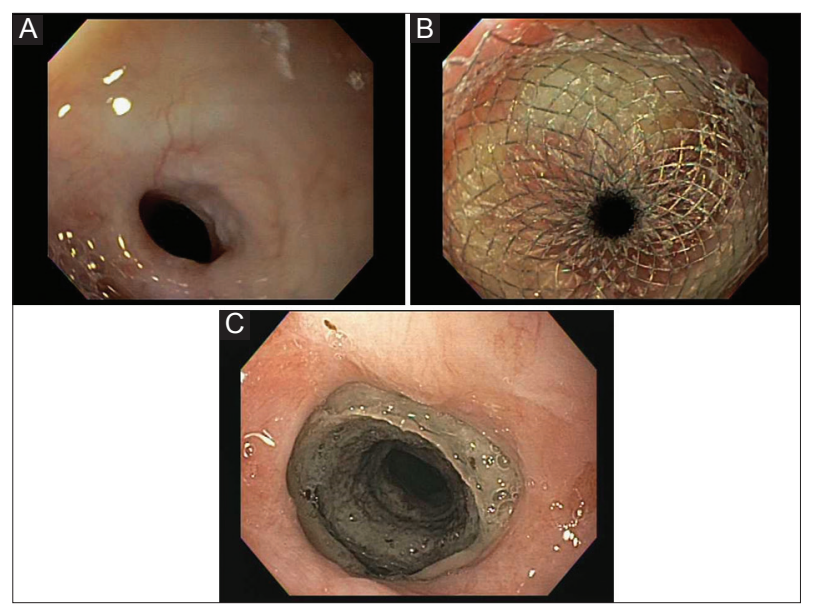

Figure 1 (A) Refractory benign esophageal stricture. (B) Same stricture after placement of a 15-mm lumen-apposing metal stent (LAMS). (C) Appearance of the LAMS in the stricture 3 months later. The stent was removed with resolution of the stricture and no recurrence of dysphagia 
Table 1 The number of patients, etiology of the GI stricture, prior therapy and other characteristics of the procedure in patients who had LAMS placed for luminal GI strictures based upon site of the stricture

\begin{tabular}{|c|c|c|c|c|c|}
\hline $\begin{array}{l}\text { Characteristics of patients } \\
\text { and/or procedure }\end{array}$ & Esophageal & Gastric & GJ/Duodenal & Colonic & Unspecified site \\
\hline Number & 22 patients & 20 patients & 35 patients & 11 patients & $\begin{array}{l}56 \text { procedures in } \\
49 \text { patients }\end{array}$ \\
\hline Etiology of GI stricture & $\begin{array}{l}\text { Anastomotic (17) } \\
\text { Caustic } \\
\text { injury (2) } \\
\text { RBES (2) } \\
\text { Radiation (1) }\end{array}$ & $\begin{array}{l}\text { Anastomotic (4) } \\
\text { Caustic injury (1) } \\
\text { PUD (4) } \\
\text { Pyloric } \\
\text { stenosis (10) } \\
\text { Malignancy (1) }\end{array}$ & $\begin{array}{l}\text { GJ Anastomotic } \\
\text { stricture (32) } \\
\text { PUD (2) } \\
\text { Chronic } \\
\text { pancreatitis (1) }\end{array}$ & $\begin{array}{l}\text { Anastomotic (10) } \\
\text { Unreported (1) }\end{array}$ & $\begin{array}{l}\text { Anastomotic (38) } \\
\text { PUD (8) } \\
\text { Radiation (1) } \\
\text { Unreported (2) }\end{array}$ \\
\hline Prior therapy & $\begin{array}{l}21 \text { patients } \\
\text { EBD } \\
\text { Intralesional } \\
\text { steroid } \\
\text { Needle knife } \\
\text { SEMS }\end{array}$ & $\begin{array}{l}13 \text { patients } \\
\text { EBD (8) } \\
\text { EBD and } \\
\text { intralesional } \\
\text { steroid (4) } \\
\text { SEMS (1) }\end{array}$ & $\begin{array}{l}28 \text { patients } \\
\text { EBD (18) } \\
\text { EBD and } \\
\text { intralesional } \\
\text { steroid (7) } \\
\text { EBD and SEMS (3) }\end{array}$ & $\begin{array}{l}8 \text { patients } \\
\text { EBD (7) } \\
\text { SEMS (1) }\end{array}$ & $\begin{array}{l}39 \text { patients } \\
\text { EBD (37) } \\
\text { EBD and } \\
\text { intralesional } \\
\text { steroid (2) } \\
\text { SEMS (13) }\end{array}$ \\
\hline Technical success & 22 & 20 & 34 & 11 & 56 \\
\hline \multicolumn{6}{|l|}{ Clinical success } \\
\hline Short term & 20 & 15 & 28 & 11 & 54 \\
\hline Long term & 14 & 15 & 26 & 7 & 15 \\
\hline Adverse events & $\begin{array}{l}5 \text { Total } \\
\text { Stent } \\
\text { migration (3) } \\
\text { Stent } \\
\text { angulation (2) }\end{array}$ & $\begin{array}{l}2 \text { Total } \\
\text { Ulceration at } \\
\text { stent site (1) } \\
\text { Post-op } \\
\text { bleeding (1) }\end{array}$ & $\begin{array}{l}6 \text { Total } \\
\text { Stent migration (3) } \\
\text { Ulceration at stent } \\
\text { site (2) } \\
\text { perforation (1) }\end{array}$ & $\begin{array}{l}1 \text { Total } \\
\text { Stent migration }\end{array}$ & $\begin{array}{l}19 \text { Total } \\
\text { Stent migration } \\
\text { Stricture } \\
\text { development } \\
\text { Stent intolerance } \\
\text { Stent occlusion } \\
\text { GIB Infection }\end{array}$ \\
\hline Follow-Up interval & 28-290 days & 28-306 days & 2-21 months & 60-290 days & $\begin{array}{l}\text { 28-480 days } \\
\text { (average } 6 \text { months) }\end{array}$ \\
\hline
\end{tabular}

EBD, endoscopic balloon dilation; GIB, gastrointestinal bleeding; GJ, gastrojejunal; PUD, peptic ulcer disease; RBES, refractory benign esophageal strictures; SEMS, self-expandable metal stent
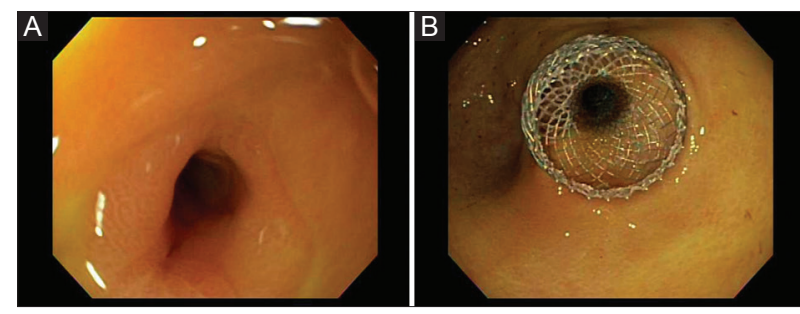

Figure 2 (A) Pyloric stenosis, probably from prior peptic ulcer disease. (B) Site of pyloric stenosis after placement of a 15-mm lumen-apposing metal stent

given 2 units of packed red blood cells (PRBCs) and underwent embolization of the posterior duodenal artery. Fifteen of the 20 patients were reported to have symptom improvement or resolution after varying amounts of stent indwell time, ranging from 28-306 days.

Santos-Fernandez et al reported 6 patients who received a LAMS for a gastric stricture [14]. One patient had a LAMS complicated by an ulcer at the stricture site after 28 days of indwell time, necessitating stent removal. Two patients had tissue overgrowth at the site of the LAMS. One patient had tissue overgrowth documented at 306 days of indwell time that resolved with endoscopic strictureplasty. Another patient developed tissue overgrowth at 183 days of indwell time leading to stent removal. However, Santos-Fernandez et al considered these patients to be clinical successes given their symptom improvement or resolution. The remaining 3 patients had no adverse events and had successful resolution of their symptoms and strictures without additional interventions.

Irani et al reported 6 patients with pyloric stenosis who had been treated with a LAMS [15]. Three of the 6 patients had symptom resolution at a median follow up of 352 days. Two of the 6 patients underwent subsequent surgical intervention and 1 patient is receiving periodic EBDs as well intralesional steroid injections.

Yang et al reviewed 3 patients with gastric strictures treated with a LAMS [16]. One patient had postprocedural bleeding requiring 2 units of PRBCs and embolization of the posterior duodenal artery. The authors speculated that the bleeding was due to unintentional mucosal injury when the catheter delivery system was advanced across the stricture. The other 2 patients had symptom resolution and showed endoscopic evidence of stricture improvement after a median of 100 days of follow up 
from stent removal.

A total of 5 additional case reports were reviewed in the literature regarding a LAMS used to treat a gastric stricture [17-20]. In all the case reports, no adverse events were reported. All 5 patients had improvement in symptoms at 1-6 months of follow up.

\section{Duodenal and gastrojejunal strictures}

To date, 36 patients in the reviewed literature had a LAMS used to treat a small bowel or a gastrojejunal (GJ) stricture [14-17,20-22]. Etiology for small-bowel strictures included peptic ulcer-associated stricture and chronic pancreatitis-associated stricture. Refractory GJ anastomotic strictures were seen in 33 cases, the most common indication for use of a LAMS in the treatment of any GI stricture. Twenty-nine of the 36 patients had had previous endoscopic therapy, including EBD, intralesional steroids or SEMS. Of the 36 patients with a GJ anastomotic stricture or duodenal stricture treated with a LAMS, only 6 patients had an adverse event reported. Three patients had stent migration, 2 patients had ulcer formation at the site of the stent and 1 patient suffered a perforation immediately corrected by surgery. One patient had an asymptomatic migration, discovered during endoscopy for planned stent removal, and was found to have had resolution of their stricture. Twenty-seven of the 36 patients had symptom improvement or resolution after stent removal. No stricture recurrence was reported in these patients.

Santos-Fernandez et al reported on 3 patients with duodenal strictures treated with a LAMS and 1 patient with a GJ anastomotic stricture [14]. Three of the 4 patients had successful resolution of symptoms and strictures without additional interventions. One patient had a proximal migration of the LAMS, after 150 days of indwell time, treated by removal of the first device and placement of another LAMS. Another case in this series experienced a distal migration; however, upon removal of the stent the stricture had resolved and no further interventions were required.

Irani et al reported on 13 patients with GJ anastomotic strictures treated with a LAMS [15]. Eleven of the 13 patients had been previously treated with EBD and 7 with EBD and intralesional steroid injections. Nine of the 13 patients had resolution of symptoms without the need for further intervention at a median of 301 days of follow up. Four patients experienced adverse events. Two patients had stent migration occur, 1 of whom also had ulceration and bleeding at the stricture site. Two patients had severe pain necessitating stent removal and at the time of removal ulcer formation at the stricture sites was noted in both patients; 1 patient had also developed a stricture proximal to the LAMS.

Yang et al reported on 14 patients with GJ anastomotic strictures treated with a LAMS [16]. Thirteen patients had been previously treated with EBD and 2 patients with a SEMS. Of the 14 patients treated with a LAMS, 10 patients achieved symptom and stricture resolution after a median of 100 days of follow up after stent removal. One patient did not respond to LAMS therapy but it was not reported why. One patient was symptomatic after stent removal and underwent repeat stent placement. Two patients had adverse events: 1 patient had perforation following stent placement, requiring surgical revision, and 1 patient had severe pain after stent placement, necessitating removal.

\section{Colonic/rectal strictures}

A total of 11 patients in the reviewed literature had a LAMS used to treat a colonic stricture [14-16,23]. Ten patients had colonic anastomotic strictures and 1 other patient had a colonic stricture with the etiology unreported. Eight of the 11 patients had been previously treated with endoscopic therapy, 8 patients with EBD and 1 patient with a SEMS that had migrated. Of the 11 patients with a colonic stricture treated with a LAMS, only 1 adverse event was reported: migration of the stent. Seven of the 11 patients had symptom and stricture resolution. Three patients had recurrence of symptoms after stent removal. One was referred for surgical management of the stricture and 2 had repeat stents placed.

\section{Unspecified stricture site}

Bazerbachi et al describe the largest retrospective trial to date on the use of LAMS in the treatment of GI strictures [24]. They reported on 49 patients with GI strictures who underwent 56 procedures. Since they did not report the exact location of the GI strictures, this trial will be reviewed separately. Of the 49 strictures, 39 were considered refractory, previously treated with two endoscopic procedures without improvement in stricture appearance. The etiology of the strictures was anastomotic strictures, pyloric stenosis, peptic ulcerassociated strictures, radiation-induced strictures and other (2 patients with etiology not reported). Initial resolution of symptoms was achieved in 54 of 56 cases. Fifteen patients had sustained symptom and stricture resolution after stent removal. Nineteen patients had the LAMS left in place and symptom resolution was not reported. Seventeen of the 56 cases had stricture recurrence and required additional interventions. Stent migration occurred in 10 of 56 cases. The average duration of stent dwell time until migration was 54 (range 6-215) days. Only 2 patients had symptoms indicative of migration; the rest were incidentally noted in follow-up endoscopy or routine imaging. Adverse events occurred in 19 of the 56 cases and included stricture development adjacent to the stent, stent occlusion, stent intolerance necessitating removal, minor GI bleed, and infection.

\section{Discussion}

GI strictures usually present with symptoms of abdominal pain, cramping, weight loss or-depending on the locationdysphagia, nausea and vomiting. Diagnosis is usually made with imaging and confirmed via endoscopy. A total of 138 patients were reviewed in the 4 retrospective studies and 13 case 
reports [13-24]. The patients were predominantly female, with ages ranging from 18-86 years. Of the 138 patients, only 1 patient underwent LAMS placement for a malignant associated stricture and was successfully treated with no further symptoms at 4 weeks of follow up [19]. Of the 138 patients, 109 had failed prior treatment with standard endoscopic therapy. Benign anastomotic stricture was the most common etiology, occurring in 101 of the 138 patients. No deaths were attributed to LAMS.

\section{Future directions}

LAMS have a unique design that has enabled them to be used off-label for the treatment of short luminal strictures. There are three commercially available LAMS worldwide: AXIOS $^{\mathrm{rm}}$ stent (Boston Scientific, Natick MA, United States), NAGI ${ }^{\mathrm{m}}$ stent (Taewoong Medical Co., Ltd., Ilsan, South Korea) and SPAXUS ${ }^{\text {ma }}$ stent (Taewoong Medical Co., Ltd., Ilsan, South Korea), each having slightly different geometry, size, and design. Future studies could compare the various stents regarding their safety and efficacy in use for luminal strictures. Data are limited on the period of time that LAMS can safely remain in the lumen of the GI tract. Further studies are needed to determine the period of time LAMS can be left in place when used for GI strictures and to determine any potential risks. Other novel uses are being investigated, such as treatment for gastroparesis via LAMS across the pylorus (Fig. 3). LAMS as destination therapy for luminal strictures was used in some patients in the reviewed literature [14]. Follow-up studies in these patients could be a starting point. Additionally, future studies could compare LAMS to other traditional therapies (EBD, intralesional steroids or traditional SEMS) for the treatment of luminal strictures.

\section{Concluding remarks}

LAMS can provide a viable alternative for treating short

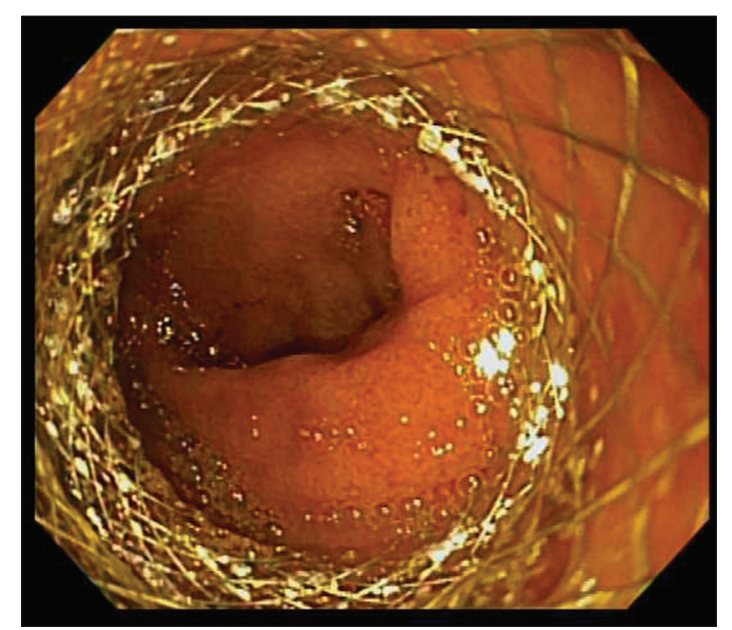

Figure 3 Lumen-apposing metal stent placed across the pylorus to treat refractory gastroparesis luminal strictures of various etiologies throughout the GI tract. LAMS appear to be safe when used to treat GI luminal strictures; only 2 of the 138 cases in the reviewed literature had immediate adverse events warranting hospitalization. A total adverse event rate of $32.5 \%$ (45 of 138 cases) was reported in the reviewed literature, with $40 \%$ of adverse events being stent migration. LAMS appear to be effective, as nearly $58 \%$ of patients in the reviewed studies had symptom and stricture resolution after stent removal. The unique design of LAMS may reduce migration rates and improve patient tolerance. However, more data are needed to determine the long-term safety and efficacy of LAMS in the treatment of luminal strictures. Overall, LAMS represent an important alternative to traditional endoscopic options in patients with short GI luminal strictures.

\section{References}

1. Kochhar R, Kochhar S. Endoscopic balloon dilation for benign gastric outlet obstruction in adults. World $J$ Gastrointest Endosc 2010;2:29-35.

2. Ramage JI Jr, Rumalla A, Baron $\mathrm{TH}$, et al. A prospective, randomized, double-blind, placebo-controlled trial of endoscopic steroid injection therapy for recalcitrant esophageal peptic strictures. Am J Gastroenterol 2005;100:2419-2425.

3. Jain D, Sandhu N, Singhal S. Endoscopic electrocautery incision therapy for benign lower gastrointestinal tract anastomotic strictures. Ann Gastroenterol 2017;30:473-485.

4. Fuccio L, Hassan C, Frazzoni L, Miglio R, Repici A. Clinical outcomes following stent placement in refractory benign esophageal stricture: a systematic review and meta-analysis. Endoscopy 2016;48:141-148.

5. Suzuki T, Siddiqui A, Taylor LJ, et al. Clinical outcomes, efficacy, and adverse events in patients undergoing esophageal stent placement for benign indications: a large multicenter study. J Clin Gastroenterol 2016;50:373-378.

6. Irani S, Baron TH, Gluck M, Gan I, Ross AS, Kozarek RA. Preventing migration of fully covered esophageal stents with an over-the-scope clip device (with videos). Gastrointest Endosc 2014;79:844-851.

7. Ngamruengphong S, Sharaiha RZ, Sethi A, et al. Endoscopic suturing for the prevention of stent migration in benign upper gastrointestinal conditions: a comparative multicenter study. Endoscopy 2016;48:802-808.

8. Adler DG, Shah J, Nieto J, Binmoeller K, Bhat Y, Taylor LJ, Siddiqui AA. Placement of lumen-apposing metal stents to drain pseudocysts and walled-off pancreatic necrosis can be safely performed on an outpatient basis: A multicenter study. Endosc Ultrasound 2018 May 17 [Epub ahead of print]. doi: 10.4103/eus.eus_30_17

9. Siddiqui AA, Adler DG, Nieto J, et al. EUS-guided drainage of peripancreatic fluid collections and necrosis by using a novel lumen-apposing stent: a large retrospective, multicenter U.S. experience (with videos). Gastrointest Endosc 2016;83:699-707.

10. Kalva NR, Vanar V, Forcione D, Bechtold ML, Puli SR. Efficacy and safety of lumen apposing self-expandable metal stents for EUS guided cholecystostomy: a meta-analysis and systematic review. Can J Gastroenterol Hepatol 2018;2018:7070961.

11. Mouradides C, Taha A, Borbath I, Deprez PH, Moreels TG. How to treat intestinal obstruction due to malignant recurrence after Whipple's resection for pancreatic head cancer: Description of 2 new endoscopic techniques. World J Gastroenterol 2017;23:6181-6186.

12. Consiglieri CF, Escobar I, Gornals JB. EUS-guided transesophageal 
drainage of a mediastinal abscess using a diabolo-shaped lumenapposing metal stent. Gastrointest Endosc 2015;81:221-222.

13. Adler DG. Lumen-apposing metal stents for the treatment of refractory benign esophageal strictures. Am J Gastroenterol 2017;112:516-517.

14. Santos-Fernandez J, Paiji C, Shakhatreh M, et al. Lumenapposing metal stents for benign gastrointestinal tract strictures: An international multicenter experience. World $J$ Gastrointest Endosc 2017;9:571-578.

15. Irani S, Jalaj S, Ross A, Larsen M, Grimm IS, Baron TH. Use of a lumen-apposing metal stent to treat GI strictures (with videos). Gastrointest Endosc 2017;85:1285-1289.

16. Yang D, Nieto JM, Siddiqui A, et al. Lumen-apposing covered selfexpandable metal stents for short benign gastrointestinal strictures: a multicenter study. Endoscopy 2017;49:327-333.

17. Majumder S, Buttar NS, Gostout C, et al. Lumen-apposing covered self-expanding metal stent for management of benign gastrointestinal strictures. Endosc Int Open 2016;4:E96-E101.

18. Adler DG. Use of a lumen-apposing metal stent to treat pyloric stenosis. Gastrointest Endosc 2017;86:742-743.

19. Trindade AJ, Hung CK, Zimmerman HM, Benias PC. Placement of a lumen-apposing metal stent for palliation of malignant pyloric stenosis. Endoscopy 2018;50:E210-E211.

20. Pinson R, Pathirana I, Magulick J, Domanski J, Okoh E, Womeldorph C. Novel use of a uniquely designed, lumenapposing, metal stent in benign gastric outlet obstruction in two patients. ACG Case Rep J 2017;4:e20.

21. Tyberg A, Desai A, Zerbo S, Nieto J, Kahaleh M. Endoscopic management of an anastomotic stricture using a lumen-apposing metal stent. Gastrointest Endosc 2016;83:464-465.

22. Uchima H, Abu-Suboh M, Mata A, Cruz M, Espinos J. Lumenapposing metal stent for the treatment of refractory gastrojejunal anastomotic stricture after laparoscopic gastric bypass. Gastrointest Endosc 2016;83:251.

23. Martínez Alcalá F, Martínez-Alcalá García FR, Sánchez-Yague A, Martínez-Alcalá García A, Ciria Avila JA, Perez Pozo JM. Treatment of a benign, anastomotic refractory rectal stricture with an AXIOS stent. Endoscopy 2015;47 Suppl 1 UCTN: E413-E414.

24. Bazerbachi F, Heffley JD, Abu Dayyeh BK, et al. Safety and efficacy of coaxial lumen-apposing metal stents in the management of refractory gastrointestinal luminal strictures: a multicenter study. Endosc Int Open 2017;5:E861-E867. 